\title{
O LUGAR DAS MULHERES: GÊNERO E INCLUSÃO DIGITAL
}

\section{Ariane Durce Maciel}

Doutora em Ciência da Informação (PPGCI - IBICT/UFRJ).

Trabalha no IBICT.

\begin{abstract}
Resumo
$\mathrm{O}$ artigo faz um panorama das conquistas femininas, buscando identificar as diferenças de gênero no uso e apropriação das Tecnologias de Informação e Comunicação (TICs) como ferramenta de aumento da cidadania das mulheres na busca da igualdade entre os gêneros. A partir de pesquisas bibliográficas e documentais, verifica-se: o confronto inclusão versus exclusão social, com base no acesso às tecnologias digitais no contexto da sociedade do conhecimento; a história de vida e de lutas das mulheres brasileiras permite que as jovens de hoje se deparem com um ambiente mais igualitário em relação às oportunidades abertas pelo acesso à rede mundial de computadores.
\end{abstract}

Palavras-chave

Gênero. Inclusão digital. Tecnologias de Informação e Comunicação (TICs). Mulheres.

\section{A PLACE FOR WOMEN: GENDER AND DIGITAL INCLUSION}

\begin{abstract}
In this article, we trace a general overview of women's achievements, trying to identify differences in gender in the use and appropriation of information and communication technologies (ICTs) as a tool to increase women's citizenship in their search for gender equality. Regarding bibliographical and documental research, it is possible to observe: the conflict social inclusion versus social exclusion, based on access to digital technologies, in the context of the knowledge society; the history of Brazilian women's lives and struggle which allows young women today to encounter a more egalitarian environment in relation to the opportunities that are open through access to a global network of computers.
\end{abstract}

\section{Keywords}

Gender. Digital Inclusion. Information and Communication Technologies (ICTs). Women. 


\section{MULHERES E TECNOLOGIA}

O momento contemporâneo, no qual a marca da sociedade atual é ser "Sociedade do Conhecimento", onde o fluxo de informações é intenso e o conhecimento passa a ser a vantagem comparativa mais decisiva, colocando novos desafios para o empoderamento das mulheres, nos faz olhar para a Inclusão Digital das mulheres como uma ferramenta de reforço de cidadania, de combate à exclusão e à pobreza.

As mudanças constantes das fronteiras entre a esfera privada atribuída às mulheres, especialmente dada à natureza das atividades por elas desenvolvidas, e as esferas públicas tradicionalmente dominadas por homens, devido à mudança na organização social provocada pelas novas TICs, fazem com que o acesso às novas tecnologias seja o próprio instrumento de transformação social e de desenvolvimento de processos, instrumentos, técnicas e canais de comunicação que podem reforçar a atuação das mulheres como sujeitos políticos e comunicacionais.

Este deslocamento de fronteiras levou a uma ruptura de papéis de gênero tradicionais, assim como outras mudanças sociais, trazendo o surgimento de novas hierarquias de poder que tendem a provocar mudanças na ordem, anteriormente estabelecida e decorrente do acesso desigual e estratificado de indivíduos e grupos às tecnologias digitais.

No combate às desigualdades sociais é sempre cabível a pergunta sobre que fatores seriam mais estratégicos, e a resposta certamente está vinculada a um dos problemas mais comprometedores da sociedade, a exclusão social. A mesma indagação pode ser levantada quando se busca o conceito de desenvolvimento humano e quais seriam os fatores mais diretamente a ele ligados.

Assumindo-se como fator de desenvolvimento a existência de "oportunidade", a inclusão digital é capaz de abrir um horizonte mais visível, ainda que virtual, de oportunidades e capaz de promover o sexo feminino apto a usufruir de novas oportunidades.

Pois aptas, as mulheres sempre foram, como também ainda serão, por questões históricas e culturais, barradas no acesso às oportunidades. A mulher efetivamente excluída é aquela que se quer sabe, e é coibida a saber que não tem direito, e assim se torna incapaz de elaborar postura crítica de que são excluídas porque assim são mantidas. 
O não acesso, especialmente, às tecnologias digitais é uma história de exclusão injusta, imposta, mantida e cultivada. "Mulher não foi feita para lidar com máquinas". Quantas vezes já ouvimos esta frase? E de tanto se repetir ideias e frases como esta, as próprias mulheres acabaram criando uma consciência de que não são capazes de lidar com as novas tecnologias. O preconceito em relação à capacidade da mulher em lidar com a tecnologia é uma das principais barreiras de acesso dentro e fora dos grupos de mulheres.

A ideia de que a tecnologia tem sempre um viés masculino talvez possa ser justificada também por algumas descobertas tecnológicas, como por exemplo, a utilização do forno microondas para cozimento de alimentos. O americano Percy Spencer foi o descobridor dessa tecnologia, em 1945, quando trabalhava em uma empresa que fabricava magnetrons para aparelhos de radar, e ao desenvolver uma de suas experiências, em um aparelho de radar ativo, observou que uma barra de chocolate que tinha no seu bolso havia se derretido. Percy não era nenhum estranho às descobertas e experiências, devido ao seu suporte a 120 patentes, e entendeu perfeitamente o que tinha acontecido.

O primeiro alimento a ser cozido com microondas foi a pipoca e o segundo um ovo, que cozinhou de dentro para fora e explodiu devido à pressão. Do patenteamento da tecnologia de cozimento por microondas ao desenvolvimento dos primeiros fornos foram necessários mais alguns anos de pesquisas, dado que no início o microondas foi usado nas cozinhas de navios militares. Assim, uma tecnologia desenvolvida por homem e destinada ao ambiente masculino, e para a esfera pública, torna-se uma invenção de enorme repercussão para o ambiente doméstico, a esfera privada (WAJCMAN, 2000).

Coincidentemente no ano de 1946, surgia o Eniac (Electrical Numerical Integrator and Computer), o primeiro computador digital eletrônico de grande escala. Criado em fevereiro de 1946, pelos cientistas norte-americanos John Eckert e John Mauchly, da Electronic Control Company. O ENIAC começou a ser desenvolvido em 1943 durante a II Guerra Mundial para computar trajetórias táticas que exigissem conhecimento substancial em matemática, mas só se tornou operacional após o final da guerra.

O computador dessa época pesava 30 toneladas, media 5,50 m de altura e $25 \mathrm{~m}$ de comprimento e ocupava $180 \mathrm{~m}^{2}$ de área construída. Foi construído sobre estruturas metálicas com 2,75 m de altura e contava com 70 mil resistores e entre 17.468 e 18.000 válvulas a vácuo ocupando a área de um ginásio desportivo. Segundo Tom Forester, quando acionado pela primeira vez, o ENIAC consumiu tanta energia que as luzes da cidade de 
Filadélfia piscaram. Esta máquina não tinha sistema operacional e seu funcionamento era parecido com uma calculadora simples de hoje.

O ENIAC, assim como uma calculadora, tinha de ser operado manualmente, sendo programado através de milhares de interruptores. Para programá-lo era necessária uma grande quantidade de pessoas que percorriam as longas filas de interruptores dando ao ENIAC as instruções necessárias para computar, ou seja, calcular. Existia uma equipe de 80 mulheres na Universidade da Pensilvânia cuja função era calcular manualmente as equações diferenciais necessárias para os cálculos de balística. $\mathrm{O}$ exército chamava a função destas pessoas: computadores.

Quando o ENIAC ficou pronto, seis mulheres "computador" foram escolhidas para testarem a nova máquina. Curiosamente, o termo "computador" (masculino desde sua concepção inicial) deixou de estar associado às pessoas que operavam a máquina para dar nome à máquina propriamente dita, uma vez que de fato a máquina passou a realizar as contas que antes eram realizadas por essas pessoas. E por que não chamá-la de computadora?

Em termos práticos, a questão colocada é como dotar as mulheres excluídas das mesmas armas usadas pelos excluintes e propiciá-las à emancipação solidária.

Destacamos aqui um projeto de Inclusão Digital: Cyberela, voltado à inclusão de mulheres, que foi desenvolvido pela organização não governamental CEMINA Comunicação, Educação e Informação em Gênero, que há mais de duas décadas se dedica à promoção de cidadania feminina através do rádio. O Programa Fala Mulher foi lançado em 08 de março de 1988, promovendo iniciativas culturais, políticas e sociais de mulheres através da rádio. $\mathrm{O}$ programa também proporcionava respostas às perguntas e aos anseios femininos, registrando assim inúmeras histórias de dor e alegria.

Com a expansão da telefonia e da Internet no Brasil, em 1999, o CEMINA criou o Projeto Cyberela, que continha duas vertentes: a de disseminação de conteúdo radiofônico através do portal www.radiofalamulher e a de capacitação de comunicadoras populares que passaram a ser as "Cinderelas do Cyberespaço", que foi a fonte inspiração para o nome, por elas próprias, escolhido: Ciberelas.

As Cyberelas tinham a missão de usar as TICs para aprimorar os programas de rádio e a Internet, como meio facilitador da troca de conteúdos entre os pontos da rede. 
Tão logo a oferta de Internet em Banda Larga se tornou ponto central da política pública brasileira, foi possível viabilizar a criação de telecentros ligados à Rede Cyberela, fazendo com que as cyberelas se tornassem agentes de Inclusão Digital no Brasil. Segundo Thais Corral ${ }^{1}$ "Inclusão Digital de mulheres têm um efeito multiplicador, na medida em que as mulheres envolvidas tendem a encorajar outras a se habilitarem para o uso da TICs".

A ideia do conhecimento como vantagem comparativa mais decisiva, ilustrada nas ações pioneiras do CEMINA demonstra, sobretudo, a situação de estar disponível, à vontade para os mais necessitados, e que tem implicações no próprio conceito e contraconceito de vantagem, quando desvantagem significa o que não é igualmente distribuído.

Dentre as experiências internacionais de projetos atuais de inclusão social voltado para mulheres merece destaque o $\operatorname{CITIGEN}^{2}$ (Gender anda Citizenship in the information society) - Gênero e Cidadania na Sociedade da Informação. Essa organização visa principalmente o desenvolvimento de diálogos entre as feministas do Sul sobre as oportunidades e desafios que a Sociedade da Informação oferece para a teoria e prática feministas. A CITIGEN procura construir um quadro teórico convincente para colocar as questões de gênero na ordem do dia.

Dessa forma, a "lente de cidadania" é utilizada como a mais adequada para a construção de uma perspectiva política e na identificação de oportunidades para a prática feminista e para o empoderamento das mulheres.

Mulheres-gov é outro projeto de investigação-ação feminista, apoiado pelo IDRC ${ }^{3}$, que visa reforçar a cidadania das mulheres marginalizadas e tem compromisso com a governança local, atuando em três locais: na Índia, no Brasil e na África do Sul. As organizações parceiras são: TI para a Mudança, na Índia; Instituto Nupef (Núcleo de Estudos, Pesquisas e Formação), no Brasil, e a Universidade de Western Cape, na África do Sul.

O Instituto Nupef é um espaço dedicado à reflexão, análise, produção de conhecimento e formação, principalmente, centrado em questões relacioandas às Tecnologias da Informação e Comunicação e suas relações políticas com os direitos humanos, a democracia, o desenvolvimento e a justiça social.

\footnotetext{
${ }^{1}$ Fundadora e Coordenadora Geral do CEMINA.

${ }^{2}$ As informações sobre a CITIGEN podem ser acessadas em: http://www.gender-is-citizenship.net/

${ }^{3}$ Informações sobre o IDRC podem ser acesadas em http://www.idrc.ca/EN/Pages/default.aspx
} 


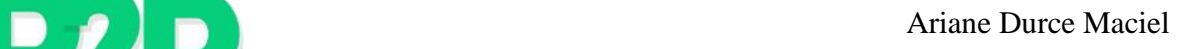

Em cada um dos três países mencionados, o projeto pretende desenvolver um modelo sustentável de intervenção técnico-social para permitir que os coletivos de mulheres marginalizadas tenham engajamento ativo com estruturas de governança e da articulação e negociação coletiva de seus interesses; e a construção de redes peer-to-peer para aumentar sua participação política. Em suma, pretende explorar as condições para uma cidadania ativa das mulheres por meio de tecnologias digitais.

\section{MULHERES E EXCLUSÃO SOCIAL}

Toda a existência humana nos remete às bases biológicas que se traduzem na diferenciação entre machos e fêmeas, apresentadas como classes de gênero. Assim, como assinala CARLOTO (2001), a produção social da existência, em todas as sociedades conhecidas, implica na intervenção conjunta dos dois gêneros, o masculino e o feminino, onde cada um representa uma particular contribuição na produção e reprodução da própria existência.

...na produção social de sua existência, os homens entram em relações determinadas, necessárias, independentes de sua vontade; estas relações de produção correspondem a um grau determinado de desenvolvimento de suas forças produtivos materiais. $\mathrm{O}$ conjunto destas relações de produção constitui a estrutura econômica da sociedade, a base real, sobre a qual se eleva uma superestrutura jurídica e política e a qual correspondem formas sociais determinadas de consciência. Não é a consciência dos homens o que determina a realidade; ao contrário, a realidade social é a que determina sua consciência (IZQUIERDO, APUD LAURENTIS, 1994).

Dessa forma, cada sociedade estabelece as concepções de masculino e feminino, nas quais todos os seres humanos são classificados. Assim, cria-se um sistema simbólico ou um sistema de significações que relaciona o sexo a conteúdos culturais de acordo com valores e hierarquias sociais. Cabe aqui destacar que, a despeito das diferenças culturais que possam afetar as significações de cada uma das categorias, quais sejam macho e fêmea, todos esses sistemas, ainda que simbólicos, de sexo-gênero estão sempre intimamente ligados a fatores políticos e econômicos na sociedade.

Portanto, a construção cultural do sexo em gênero e a assimetria que caracteriza todos os sistemas de gênero, nas diferentes culturas, acaba por se traduzir sistematicamente em uma organização da desigualdade social. Para LAURETIS (1994) o sistema sexo- 
gênero é tanto uma construção sociocultural quanto um aparato semiótico, um sistema de representações que atribui significado (identidade, valor, prestígio, posição de parentesco, status dentro da hierarquia social etc) a indivíduos dentro da sociedade. Para o pesquisador, o termo gênero é uma representação não apenas no sentido de que cada palavra, cada signo, representa seu referente, seja ele um objeto, uma coisa, ou ser animado. O termo "gênero" é, na verdade, a representação de uma relação, a relação de pertencer a uma classe, a um grupo ou a uma categoria. Assim, gênero representa não um indivíduo e sim uma relação, uma relação social; em outras palavras, representa um indivíduo por meio de uma classe.

Amartya $\mathrm{Sen}^{4}$ trata da relação do desenvolvimento econômico e gênero, mostrando que as diferenças entre homens e mulheres vão desde questões relacionadas ao acesso à saúde e à educação, até condições de trabalho e remuneração. A questão das diferenças de gênero torna-se ainda mais perversa para mulheres e meninas que são pobres, que vivem em áreas remotas, que são deficientes ou que pertencem a grupos minoritários. Um número excessivo de meninas e mulheres ainda está morrendo, respectivamente, na infância e na idade reprodutiva. As mulheres ainda ficam atrás em rendimentos e produtividade, e na força de suas vozes na sociedade. Em algumas áreas, tais como educação, existe hoje uma grande diferença de gênero em comparação a homens e meninos (SEN, 2000).

As desvantagens em termos de saúde que surgem na mortalidade excessiva relativa de meninas e mulheres se enquadram nesta categoria. E o mesmo ocorre com outros hiatos persistentes de gênero, incluindo segregação no mercado de trabalho, disparidades salariais de gênero, diferenças entre homem/mulher em termos de responsabilidade, que tendem a rotular o trabalho feminino sempre com características de complementaridade às tarefas domésticas, sempre prioritariamente a cargo delas.

Outras diferenças ocorrem ainda na posse de bens, assim como restrições na capacidade de decidir das mulheres nas esferas privada e pública.

O Relatório sobre Igualdade de Gênero e Desenvolvimento, do Banco Mundial, enfoca o papel das tecnologias de informação e comunicação na redução das restrições de tempo e mobilidade que as mulheres enfrentam para acessar e participar do mercado de trabalho (BANCO MUNDIAL, 2012).

\footnotetext{
${ }^{4}$ Mestre pelo Trinity College, em Cambridge vencedor do prêmio Nobel de Economia em 1998.
} 
A relação entre gêneros permeia as interações sociais e é reflexo das desigualdades ainda hoje verificadas. As TICs estão para as mulheres como uma ferramenta para acesso a dados e informação e como recurso, inclusive, para tornar as informações acessíveis às outras mulheres.

No campo da Educação foi preciso que, em 1827, uma Lei permitisse às mulheres frequentarem as escolas elementares. Sendo que apenas 52 anos mais tarde, em 1879, fosse facultado o ingresso ao ensino superior. Para Academia Brasileira de Letras foram necessários mais 100 anos, em 1977, para que as portas fossem abertas à primeira mulher, Rachel de Queirós, e aproximadamente mais outros 20 anos para que Nélida Piñon assumisse, pela primeira vez, a sua presidência.

No campo das Ciências, grandes homenagens rendem-se à Marie Curie, cujo nome de solteira era Marie Sklodowska, nascida na atua capital da Polônia, Varsóvia, em 07 de novembro de 1867, que se tornou Marie Curie quando se casou com Pierre, físico que ganhou notoriedade por suas pesquisas com eletromagnetismo. Marie foi a primeira mulher a receber dois Prêmios Nobéis, sendo ela a única pessoa a receber tal premiação em áreas distintas do conhecimento. Com Pierre Curie e Antoine Henri Becquerel, Marie recebeu o Nobel de Física de 1903, “em reconhecimento aos extraordinários resultados obtidos por suas investigações conjuntas sobre os fenômenos da radiação, descoberta por Henri Becquerel".

Em 1906, sucedeu ao seu marido na cadeira de Física Geral, na Sorbonne. Durante a Primeira Guerra Mundial, Marie Curie propôs o uso da radiografia móvel para o tratamento de soldados feridos. Em 1911, em reconhecimento pelos seus serviços para o avanço da Química, com o descobrimento dos elementos rádio e polônio, o isolamento do rádio e o estudo da natureza dos compostos deste elemento, recebeu o Nobel de Química. Ressalta-se, contudo, que sua atitude generosa em não patentear o processo de isolamento do rádio permitiu que as investigações das propriedades deste elemento fossem conduzidas por toda a comunidade científica. O Nobel de Química foi-lhe atribuído no mesmo ano em que a Academia de Ciências de Paris a rejeitou como sócia, após uma votação ganha por Eduard Branly com diferença de apenas um voto. Na época, Marie, com grande esforço e determinação pessoais, graduou-se e conduziu suas pesquisas em meio à desigualdade de gênero que reinava especialmente nas universidades. Tal desigualdade era percebida no exercício do poder e na "cortesia" com que elas eram tratadas. 
Para PUGLIESE (2009), cuja dissertação de Mestrado é intitulada "Sobre o caso Marie Curie - A Radioatividade e a Subversão do Gênero", as relações que constituem homens e mulheres mutuamente - dividem (sexualmente) os atributos, definindo mente, razão e objetividade como "masculinos", e coração (e corpo), sentimento e subjetividade como "femininos", mostram como as relações de poder ressoam para a exclusão da mulher no empreendimento científico. E, por conseguinte, é como se masculino fosse sinônimo de ciência e feminino seu antônimo. $\mathrm{O}$ autor apresenta uma analogia bastante clara ao dizer que as mulheres estavam para o coração e, o privado e a reprodução, assim como os homens estariam para a razão, o público e a política. As atividades eram escalonadas de acordo com as competências sexuais. Sendo Marie Curie um nome a ser eternamente exaltado como contra exemplo dessa dura realidade, mesmo, em sua época, os espaços na família, na universidade, na academia, no Estado, na civilização, eram enquadrados a partir do corte entre homens e mulheres, e do poder que daí decorresse.

Dado que as mulheres eram proibidas de participar de qualquer atividade cívica, eram igualmente inibidas para as atividades científicas.

PUGLIESE (2009) descreve com riqueza de detalhes toda a trajetória de Marie Curie em busca de seu sonho. Seu trabalho contextualiza o pensamento da sociedade da época em relação às questões de gênero que permeavam as relações humanas. A que se frisar, todavia, a importância de Pierre, pois foi ele o primeiro a exaltar a importância do trabalho de Marie e dar a ela a visibilidade merecida. Marie tinha plena consciência de que o território no qual desejava transitar não era comum às mulheres, fato esse deixou registrado em uma nota autobiográfica: "Eu tinha ouvido sobre poucas mulheres que obtiveram sucesso em certos cursos em Petrogrado ou em outros países, e eu estava determinada a me preparar através de trabalhos preliminares para seguir seus exemplos" (Marie Curie, 1963, p.166).

Marie Curie morreu perto de Salanches, na França, em 4 de julho de 1934, de leucemia, devido, seguramente, à exposição maciça a radiações durante o seu trabalho.

$\mathrm{Na}$ política, a trajetória das mulheres, bem como suas conquistas, em todos os campos, é marcada por trabalho árduo e obstinado e, muitas vezes, por sofrimento e doação.

Como precursora dos direitos das mulheres no Brasil, a deputada Nísia Floresta, eleita em 1932, no Rio Grande do Norte, defendia o acesso à educação e uma posição social 
mais alta para as mulheres. Nesse mesmo ano publicou livro "Direito das mulheres e injustiça dos homens".

Dentre outros fatos, no mínimo curiosos, em uma trajetória marcada por preconceito e discriminações que as mulheres enfrentaram ainda 1941, no Estado Novo de Getúlio Vargas, está o veto à prática de esportes considerados incompatíveis com suas condições: luta de qualquer natureza, futebol de salão, futebol de praia, polo, polo aquático, halterofilismo e beisebol. Em 1964, o Conselho Nacional de Desportos (CND) proibiu a prática do futebol feminino no Brasil - decisão só revogada em 1981. Já em 2006, a jogadora Marta foi eleita a melhor do mundo - fato que se repetiu por quatro anos consecutivos.

Entre as conquistas femininas mais expressivas, do último século no Brasil, está a do voto feminino, que passou a valer apenas em 1932, sendo que a primeira prefeita eleita na história do país foi Alzira Soriano de Souza, na cidade de Lages, em Santa Catarina, no ano de 1928. Ela nunca assumiu o mandato. A Comissão de Poderes do Senado, daquela época, impediu que a eleita tomasse posse e anulou os votos de todas as mulheres da cidade.

Outro grande marco da história política do país foi a participação das mulheres no movimento cívico que conduziu os trabalhos da Assembleia Nacional Constituinte de 1986 que também merece destaque. O Congresso recebeu em seus corredores e galerias a presença ativa da população, contando nas manifestações de rua e em seus movimentos sociais com a participação feminina.

$\mathrm{Na}$ instalação das estruturas fundamentais da Assembleia Constituinte, a Mesa da constituinte, a relatoria, os partidos políticos e seus líderes conviveram com presença feminina oficial com eleição de 26 mulheres para a Constituinte de 1986. Sob o ponto de vista histórico, esse foi um quadro inédito, uma vez que em 1934 a participação feminina se restringiu a apenas Carlota Pereira de Queiroz. Já para a de 1946, não houve nenhuma mulher eleita. Até esta data apenas 15 mulheres haviam cumprido mandato na Câmara Federal. Para o Senado, apenas quatro tinham exercido o mandato em substituição aos titulares. As constituintes eleitas em 1986 superaram todos os marcos eleitorais anteriores, apresentando o maior número total de mulheres que já passaram pelo Congresso Nacional com mandato próprio em toda a história da República. 
Pode-se dizer ainda que a pobreza extrema no Brasil tem gênero e cor. Dos 8,9 milhões de pessoas que vivem em miséria extrema no Brasil, a maioria é composta por mulheres negras e suas filhas e filhos. As famílias chefiadas por mulheres negras têm renda equivalente à metade da renda das famílias chefiadas por mulheres brancas. E a escolaridade das mulheres negras é $1 / 4$ menor que a das mulheres brancas. As mulheres apresentam ainda o maior número de anos de estudo do que os homens. Segundo o IBGE, esse número é em média de 7,4 anos de estudo (BRASIL, 2008).

\section{MULHERES, TICS E INCLUSÃO DIGITAL}

O uso das novas tecnologias de informação e comunicação, fazendo com que o computador deixe de ser apenas uma máquina de escrever melhorada, desencadeando outros usos, múltiplos e extremamente produtivos, com poder de transformar inclusive o trabalho doméstico, vai depender do tipo de programas de treinamento e formação que serão oferecidos, desde os primeiros anos da formação escolar até os mais altos níveis de escolaridade. O acesso às TICs para as mulheres figuram como fator primordial de empoderamento do trabalho feminino.

Segundo MARAZZI (2009), na virada linguística da economia, pela mobilização produtiva da comunicação, o trabalho se torna feminino, linguístico e afetivo, o que pode ser comparado ao trabalho silencioso e doméstico, e por assim se subentender o trabalho feminino, quando faz uso da expressão "o lugar das meias". A ideia feminina sobre o "lugar certo de guardar as meias" nos remete ao que seria uma busca por uma divisão mais equânime do trabalho doméstico, que avançaria na direção de se reduzir a exploração da mulher pelo homem. A atividade doméstica das mulheres passa a comportar um aumento de suas qualidades cognitivas, pois exige que estas passem a interpretar e traduzir constantemente a gama de informações que circulam em torno do contexto no qual a família está inserida.

A tecnologia e seus desenvolvimentos atuais têm eliminado uma série de atividades fisicamente cansativas no trabalho vivo doméstico, fazendo com que esse se torne cada vez mais comunicativo e relacional, e, por sua vez, aumentando sua qualidade e quantidade. As diferenças de gênero quanto ao acesso às TIC se devem em parte ao uso do 
tempo que podem resultar de normas profundamente enraizadas de distribuição de responsabilidade pelos cuidados e trabalhos de casa (DEDDECA, 2008).

Ao lado das ações de inclusão das mulheres, a difusão de novas tecnologias de informação e comunicação está se transformando em criação de mais empregos e ligações mais sólidas nos mercados para mulheres, aumentando seu acesso a oportunidades econômicas e contribuindo para seu empoderamento econômico. As tecnologias de informação e comunicação estão em contínua evolução, num processo dinâmico, e, por conseguinte as diferenças entre sexos quanto ao acesso, habilidades e usos em relação à internet podem ser observadas através de análise dessas variáveis, sendo que é necessário atentar para as suas constantes mudanças.

O acesso à internet não tende a apresentar significativas diferenças por gênero ou mesmo outras variáveis sociais. Entretanto, é preciso atentar para os diferentes tipos de uso da internet e como esses usos podem seguir apresentando diferenças de gênero. Em outras palavras, à medida que olhamos de maneira mais minuciosa os dados das pesquisas apresentadas sobre o tema, podem-se ainda encontrar diferenças significativas de uso das TICs, segundo o sexo do usuário.

Os dados apresentados por Deddeca (op.cit.), a partir de uma análise de dados do IBGE/PNAD focalizando aspectos de uso da internet por estudantes, mostram, de um modo geral, que as meninas são mais criteriosas e direcionadas quanto ao uso da internet para educação e, por outro lado, os meninos apresentaram características de uso mais intenso e diversificado da internet, incluindo o uso para o lazer. Este aspecto mais comportado das mulheres no uso da internet também foi destacado por OLINTO (2008) no artigo "Meninas comportadas e meninos brincalhões".

WOLF (2010) descreve uma experiência de inclusão digital com mulheres da Cooperax, uma cooperativa de costureiras, estruturada em moldes solidários. O objetivo do projeto foi o de promover, através da inclusão digital, o empoderamento de mulheres que trabalham no setor de corte dessa organização. A inclusão digital e a metodologia utilizada, uma vez que todas são adultas, foram importantes para detectarem suas necessidades e características em conversas e em reuniões, nas quais as mulheres relataram o que precisavam e queriam aprender.

O empoderamento, conforme destacam OAKLEY e CLAYTON (2003), pode se manifestar em três grandes aspectos: maior confiança na capacidade pessoal, aumento das 
relações efetivas e ampliação do acesso aos recursos. Neste caso, segundo a conclusão dos autores, a maior contribuição foi para que essas mulheres pudessem confiar na sua capacidade de levar adiante as ações. É o poder como maior confiança, não traduzido somente pela força externa de sua presidente, mas por forças internas que elas tinham de romper, como o medo e o desestímulo.

DRABOWICZ (2014), utilizando os dados da coleta feita pelo PISA, em 2006, e comparando-os aos anos anteriores, comprovou a existência de uma tendência ao desaparecimento das diferenças de acesso à internet dos meninos em relação às meninas. Porém, em relação ao uso, o autor relata que os meninos apresentaram índice mais elevado de uso da internet para atividades de entretenimento, as quais chamou de "individuais" (jogos, download de músicas e outras), sendo por sua vez mais interessados ao aspecto tecnológico das TIC. Já com relação às meninas, o maior período tempo era dedicado às atividades relacionadas à comunicação, portanto interativas. Os resultados permitiram, ainda, que fosse atribuído ao fato dos meninos passarem maior parte do tempo em jogos.

Um dado relevante para a discussão de jogos e gênero é apresentado pela Escola Superior de Propaganda e Marketing (ESPM), que em outubro de $2013^{5}$, divulgou um estudo apontando que o público feminino equivale atualmente a $41 \%$ dos "gamers". A pesquisa divulgou ainda que as mulheres têm em média 32 anos e que para os homens essa média é de 35 anos de idade. Outro dado interessante apresentado foi o de que a preferência de $85 \%$ dos entrevistados é por usar o computador ou PC para jogar. A cultura de jogos online, ou games como são em geral tratados, carrega um viés digital machista desde sua concepção na indústria de entretenimento (a qual remonta aos anos de 1966 a 1972), por ocasião da consolidação da empresa ATARI, uma das maiores representantes do setor.

Já na década de 80, com a ascensão da empresa NINTENDO, a cultura machista se perpetuou na criação dos personagens-chave dos joguinhos, que em geral tinham sempre o papel de salvar princesas em situações de risco.

Segundo MATEAS (2004), o desejo pelo jogo é o controle do personagem, que pode ser ele próprio ou outro. A possibilidade de fazer coisas perigosas, difíceis, proibidas ou diferentes da vida real em um contexto que justifique tais ações, compõe o rol de itens que definem o processo de escolha e o modo de agir na simulação. O contexto em que se

\footnotetext{
${ }^{5}$ Pesquisa disponível em http://acervo-digital.espm.br/artigos/art/2013/332280.pdf
} 
desenvolvem os jogos permite a identificação do jogador com o personagem. Na década de 90, algumas heroínas foram criadas, inspiradas em personagens de filmes da época, representando uma abertura no mercado dos games, embora ainda enquadrados em estereótipos machistas. Tais heroínas apresentam uma estética que valoriza o corpo e muito pouco de sua real participação na trama na qual o jogo se desenvolve, o que acaba por atrair também o público masculino. Essa dinâmica ainda parece estar longe de acabar ou mesmo de perder a relevância.

HILBERT (2011) aborda a questão do acesso e uso da internet pelas mulheres numa pesquisa feita em 12 países latino-americanos ${ }^{6}$ e 13 países africanos ${ }^{7}$ entre 2005 e 2008. Segundo o autor, o fato das mulheres apresentarem menores índices de acesso e uso da internet é resultado direto das condições desfavoráveis de emprego, educação e renda. E, a partir do momento que essas condições desfavoráveis são controladas, as mulheres passam a ser usuárias mais ativas das ferramentas digitais. Dessa forma, a suposta divisão digital de gêneros se transforma em oportunidade para diminuir a desigualdade nos países em desenvolvimento. Trata-se, de melhorar o acesso ao emprego, renda, educação e aos serviços de saúde. E, portanto, os estudos que abordam a questão da divisão de gênero no acesso e uso das TIC' ao atribuírem às mulheres o que o autor chamou de certa "tecnofobia" em relação a maior habilidade masculina com a tecnologia seriam todavia inconsequentes.

Com relação aos hábitos de leitura de meninos e meninas, LARGE at ali (2002) analisaram as diferenças na busca de informação por adolescentes de escolas canadenses. Os resultados mostraram que as meninas dedicam mais tempo à leitura das páginas na internet, ao contrário dos rapazes que trocam de páginas mais vezes por minuto.

Segundo HILBERT (2011), as TIC representam oportunidades ao sexo feminino, por exemplo, para mulheres empresárias uma vez que lhes permite o acesso mundial ao $e$ bussiness, que pode ser acessado 24 horas por dia, a partir do próprio domicílio e em tempo real.

Assim as mulheres quando abraçam a tecnologia se tornam muito mais entusiasmadas e aproveitam de maneira mais produtiva as oportunidades disponibilizadas.

\footnotetext{
${ }^{6}$ Países latinos americanos: Chile, Brasil, Uruguai, México, Paraguai, El Salvador, Costa Rica, Republica Dominiana, Panamá, Honduras, Nicarágua e Equador.

${ }^{7}$ Países Africanos: Kênia, Namibia, Etiópia, Ruanda, Moçambique, Senegal, Tanzânia, Africa do Sul, Benim, Botisuana, Gan, Uganda, Costa do Marfim.
} 
Segundo o autor, ainda, as mulheres apresentam-se muito mais comunicativas, o que lhes favoreceria o uso de tecnologias que em geral são de domínio intuitivo. O autor atribui ao fato de "ser" mulher uma correlação positiva ao uso da tecnologia e, por outro lado, uma correlação negativa com empregabilidade, renda e educação.

Repensar a questão feminina de uso e acesso às TICs é uma questão política e não somente de tecnofobia ${ }^{8}$ por si só.

A divisão digital de gêneros existe apenas como um reflexo direto da existência de desigualdades relacionadas ao sexo e as ações políticas deveriam usar as habilidades comunicativas, naturais das mulheres e as suas facilidades com a mídia e suas capacidades em abraçar as novas oportunidades digitais para superar as desigualdades de gênero existentes desde longa data (HILBERT, 2011).

HILBERT (2011) conclui seu estudo enfatizando que para repensar essa questão é necessário a criação de políticas e projetos que, verdadeiramente, permitam que as meninas e as mulheres se tornem membros igualmente representadas na sociedade da informação, na sociedade digital, na sociedade em rede, na sociedade do conhecimento, ou simplesmente membros igualmente representados na sociedade, independente do nome que se queira dar.

Na matéria publicada pelo Jornal da Ciência em 20 de março de 2014, mostra-se um estudo realizado pelo programa "L'Oréal - Unesco para Mulheres na Ciência" na França, Alemanha, Espanha, Reino Unido, Estados Unidos e Japão, que as mulheres ainda são minoria na ciência. Segundo o levantamento, apenas $29 \%$ do total de pesquisadores são mulheres. Apesar do reconhecido crescimento da participação feminina, esse percentual está longe de atingir a paridade. Outra constatação apresentada foi a de que apenas cinco mulheres foram recompensadas com um Prêmio Nobel desde 1998.

Para o Brasil, alguns estudos mostram que as mulheres estão pouco representadas em alguns ramos da ciência e da tecnologia, notadamente em TICs, área que absorve apenas $20 \%$ de mulheres, sem tendência observada de crescimento (LETA et. al., 2013; OLINTO, 2009).

Os dados recentes sobre a presença feminina nas atividades de compras na internet divulgados pela pesquisa do site mercadolivre. $\operatorname{com}^{9}$, no período de 23 de fevereiro a 04 de

\footnotetext{
${ }^{8}$ Tecnofobia é o medo da tecnologia moderna. Extremizada em obras de ficção, como o livro Frankenstein ou o filme Blade Runner, no cotidiano manifesta-se como o receio em utilizar um computador.
} 
março de 2013, mostram que $96 \%$ das mulheres costumam pesquisar preços na Web. O $e$ commerce é a terceira maior atividade realizada pelas usuárias apresentando o percentual de $75 \%$ das 900 internautas do sexo feminino que participaram do estudo.

Dentre os produtos mais pesquisados pelas mulheres, destacam-se: produtos tecnológicos (87\%) e artigos de moda (48\%). Observa-se a preferência "tecnológica" feminina na atividade de compras "online". Não é a toa que o e-commerce é a terceira maior atividade realizada pelas usuárias na internet (75\%), atrás apenas de emails (90\%) e busca de informações (77\%).

Segundo Leandro Soares $(2013)^{10}$, diretor de marketplace do MercadoLivre, a busca por eletrônicos, uma tendência historicamente mais relacionada como universo masculino, vem confirmando a mudança de comportamento da compradora virtual. "As mulheres sempre influenciaram as compras da família como um todo, mas não eram vistas como ligadas em tecnologia", diz ele. A pesquisa aponta também que mais de $25 \%$ das mulheres usam dispositivos móveis, como tablets e celulares, para compras, sendo que $48 \%$ utilizaram os aparelhos porque quiseram garantir imediatamente o produto que viram em um anúncio online.

A tabela 1 revela o comportamento atual das mulheres na preferência de compras online, demonstrado pelo alto percentual de produtos eletrônicos e tecnológicos em relação ao percentual apresentado para aos demais produtos, ainda que, quando comparados aos produtos associados à moda. $\mathrm{O}$ interesse por esse tipo de artigo, especialmente se tratando de compras online, reafirma uma mudança no comportamento feminino.

9 O que as mulheres compram no e-commerce. Mercadolivre.com. 2013. Disponível em http://segredosdomercadolivre.com.br/blog/o-que-as-mulheres- compram-no-e-commerce. Acesso em 20 de janeiro de 2014.

${ }^{10}$ Ibid. 


\section{D O lugar das mulheres: gênero e inclusão digital}

Tabela 1: Produtos que as mulheres brasileiras querem comprar pela web.

\begin{tabular}{l|l}
\hline Produtos & \% \\
\hline $\begin{array}{l}\text { Eletrônicos/tecnologia (tablets, smartphones, câmeras digitais, } \\
\text { notebooks, GPS, TVs e outros). }\end{array}$ & 74 \\
\hline Moda (roupas, sapatos, cintos, relógios, joias e bijuterias). & 42 \\
\hline Livros & 35,5 \\
\hline Artigos para crianças & 29 \\
\hline Artigos para decoração & 27 \\
\hline
\end{tabular}

Fonte: O que as mulheres compram no e-commerce. Mercadolivre.com. 2013. Disponível em http://segredosdomercadolivre.com.br/blog/o-que-as-mulheres- compram-no-e-commerce. Acesso em 20 de janeiro de 2014.

\section{CONSIDERAÇÕES FINAIS}

Inclusão Digital e Inclusão Social são conceitos que nem sempre estiveram juntos. Se o significado deles é entendido conjuntamente é porque um longo caminho foi percorrido tanto na pesquisa como na elaboração e implementação de políticas públicas que buscam prover, promover e incentivar a inclusão dos indivíduos na era digital.

Os costumes de não participação das mulheres estão profundamente enraizados na sociedade e acabam por causar certa perplexidade até nas próprias mulheres, quando na verdade uma situação como a estampada no quadro apresentado no artigo acena para uma mudança para um claro interesse por TICs.

A emergência do mundo digital trouxe uma tecnologia nova que passou a ditar a forma como o conhecimento é produzido e compartilhado. A maneira como escrevemos, aprendemos, enviamos conteúdo (intelectual, cultural, artístico e/ou informal) passou a ser diferente em função da tecnologia que usamos. Desde a passagem da tábua de argila aos rolos de papiro que o conhecimento vem sendo formatado de maneiras diferentes.

Tratar a questão gênero no âmbito da inclusão digital é resgatar a história de vida e de lutas das mulheres brasileiras, que permitiram que as jovens de hoje se deparem com um ambiente mais igualitário em relação às oportunidades abertas pelo acesso à rede mundial de computadores. 


\section{D D Ariane Durce Maciel}

"Mais mulheres incluídas", mais poder para as mulheres. Eis uma campanha permanente para que possamos ter uma plataforma de real igualdade de gênero no processo de empoderamento das mulheres.

Apesar de todas as inegáveis conquistas até hoje galgadas por representantes femininas na sociedade, acreditamos ser possível ultrapassar esse patamar, fomentando o empoderamento das mulheres pelas ações de inclusão digital voltado para atender o público feminino.

\section{REFERÊNCIAS}

BANCO MUNDIAL. Relatório sobre o Desenvolvimento Mundial 2012: igualdade de gênero e desenvolvimento. Disponível em: <http://siteresources.worldbank.org/ INTWDR2012/Resources/77781051299699968583/7786210-1315936231894/OverviewPortuguese.pdf>. Acesso em: 15 jun. 2013.

BRASIL. Ministério das Comunicações. Cartilha do programa do GESAC. Brasília: GESAC, 2007. Disponível em: <http://livroaberto.ibict.br/handle/1/854>. Acesso em: 25 maio 2013.

CARLOTO, C.M. O conceito de gênero e sua importância para a análise das relações sociais. Serv. Soc. Rev., Londrina, v. 3, n. 2, p. 201-213, jan./jun. 2001. Disponível em: <http://www.uel.br/revistas/ssrevista/n2v3.pdf\#page=83>. Acesso em: 28 jan. 2013.

DEDDECA, C. S. Regimes de trabalho, uso do tempo e desigualdade entre homens e mulheres. In. COSTA, Albertina de Oliveira; et. al. (Org.). Mercado de Trabalho e Gênero: comparações internacionais. Rio de Janeiro: FGV, 2008. p. 279-297.

INSTITUTO BRASILEIRO DE INFORMAÇÃO E ESTATÍSTICA (IBGE). Censo demográfico 2010: trabalho e rendimento: resultados da amostra. Rio de Janeiro: 2010.

IBGE/PNAD (Instituto Brasileiro de Geografia e Estatística - Pesquisa Nacional por Amostra de Domicilios 2009) 2010. Síntese dos Indicadores. Rio de Janeiro: IBGE, 2010. 


\section{P D O lugar das mulheres: gênero e inclusão digital}

IZQUIERDO, M.J. Bases materiais del sistema sexo/gênero. São Paulo: SOF, (199?). Mimeografado.

LAURETIS, T. A tecnologia do gênero. In: HOLLANDA, B.H. Tendências e impasses: o feminismo como crítica da cultura. Rio de Janeiro: Rocco, 1994.

LETA, Jacqueline; THIJS, Bart; GLÄNZEL, Wolfgang. A macro-level study of science in Brazil: seven years later. Encontros Bibli, v. 18, p. 51-66, 2013.

MARAZZI, Christian. O lugar as meias: a virada linguística da economia e seus efeitos sobre a política. [A política do Império]. Tradução Paulo Domenech Oneto. Rio de Janeiro: Civilização Brasileira, 2009.

MATEAS, Michel. A preliminary poetics for interactive drama and game. In: WARDRIPFRUIN, Noah. (Org.). First Person: new media as story performance and game. Massachusetts: MIT Press, 2004.

OAKLEY, P.; CLAYTON, A. Monitoramento e avaliação do empoderamento. 2. ed. Londres: INTRAC, 2003. Disponível em: <http://www.polis.org.br/obras/arquivo _153.pdf>. Acesso em: 15 fev. 2014.

OLINTO, Gilda. Usuários e usos da internet: múltiplas dimensões, medidas e algumas evidências. In: ENCONTRO NACIONAL DE PESQUISA EM CIÊNCIA DA INFORMAÇÃO, 9, 2008, São Paulo. Anais... 2008. Disponível em: <http://hdl.handle.net/123456789/542>. Acesso em: 9 fev. 2014.

O QUE AS MULHERES compram no e-commerce. Mercadolivre.com. 2013. Disponível em: <http://segredosdomercadolivre.com.br/blog/o-que-as-mulheres-compram-no-ecommerce>. Acesso em: 20 jan. 2014. 
PUGLIESE, Gabriel. Sobre o caso Marie Curie: a radioatividade e a subversão do gênero. São Paulo, 2009. Orientadoras: Lilia Katri Moritz Schwarcz. 193f. Dissertação (Mestrado em Antropologia Social)- Universidade de São Paulo, Faculdade de Filosofia, Letras e Ciências Humanas, São Paulo, 2009.

SEN, A. Desenvolvimento como liberdade. São Paulo: Companhia das Letras, 2000.

WAJCMAN, Judy (2000), Reflections on gender and technology studies: In: What state is the art? Social Studies of Science, 30 (3), p. 447-64.

WOLF, Maryanne. Proust and the Squid: The Story and Science of the Reading Brain, 2010. 